\title{
Bioresorbable adhesion barrier for reducing the severity of postoperative cardiac adhesions: Focus on REPEL-CV ${ }^{\circledR}$
}

This article was published in the following Dove Press journal:

Medical Devices: Evidence and Research

II January 20II

Number of times this article has been viewed

\author{
Martin Haensig \\ Friedrich Wilhelm Mohr \\ Ardawan Julian Rastan \\ Department of Cardiac Surgery, Heart \\ Center, University of Leipzig, Leipzig, \\ Germany
}

\begin{abstract}
Treatment of a number of congenital heart defects often necessitates staged surgical intervention. In addition, substantial improvements in postoperative cardiac care and more liberal use of biological valve substitutes have resulted in many adult patients surviving to become potential candidates for reoperations to repair or replace valves or to undergo additional revascularization procedures. In all these scenarios, surgeons are confronted with cardiac adhesions, leading to an increased surgical risk. Thus, bioresorbable adhesion barriers had become of increasing interest because they are easy to use, and safe and effective. This review focuses on the mechanisms by which REPEL-CV ${ }^{\circledR}$ prevents adhesive processes, as well as the development, design, and materials used, and also summarizes efficacy studies, clinical data, safety, and current role in therapy.
\end{abstract}

Keywords: adhesion prevention, bioresorbable copolymer, cardiac reoperation

\section{Introduction}

Treatment of several congenital heart defects such as single ventricle anatomy or tetralogy of Fallot often necessitates staged surgical intervention to achieve total correction or palliation in neonates, infants, and children. In addition, substantive improvements in postoperative cardiac care and medical treatment have resulted in a significant number of adult patients also becoming potential candidates for reoperations to repair or replace valves or to undergo coronary revascularization procedures. ${ }^{1}$ In reoperations, the development of severe retrosternal or pericardial adhesions leads to an increased surgical risk. ${ }^{2}$ Sometimes these adhesions may severely complicate reoperations, making re-entry hazardous and more time-consuming. ${ }^{1}$ The anatomic orientation and visibility of critical structures like bypass grafts and coronary arteries are often impaired, associated with a higher risk of injury and a greater level of stress for the entire surgical team. ${ }^{2}$ Additionally, pericardial adhesions may act to constrict the heart, and there is evidence implicating adhesions as a cause of constrictive pericarditis associated with right ventricular dysfunction. ${ }^{1}$ Finally, reoperations due to adhesions substantially increase the risk of severe intraoperative and postoperative bleeding of cardiac and mediastinal structures, as well as sternal hemorrhage, contributing to greater periprocedural morbidity and mortality. ${ }^{3}$

Thus, various considerations have been made in the past to reduce the development of intrathoracic adhesions. However, an ideal strategy to prevent postoperative cardiac adhesion formation has not been found so far. ${ }^{4}$

In general, adhesion barriers can be classified into two groups, ie, nonresorbable and bioresorbable substitutes. Nonresorbable adhesion barriers include prosthetic
Correspondence: Ardawan J Rastan Department of Cardiac Surgery, Heart Center, University of Leipzig, Struempellstr 39, 04289 Leipzig, Germany $\mathrm{Tel}+493418651319$

Email rastan@rz.uni-leipzg.de 
and xenograft materials. ${ }^{5}$ Prosthetic barriers are silicone rubber, expanded polytetrafluorethylene (ePTFE) membrane (GoreTex $^{\mathrm{TM}}$ pericardial membrane; WL Gore \& Associates Inc, Flagstaff, AZ), polyethylene film, and Dacron mesh. ${ }^{4,6}$ Use of such surgical membranes has clearly led to facilitated sternal re-entry. ${ }^{7}$ However, clinical use of these barriers has been limited by concerns regarding an extensive inflammatory reaction resulting in fibrous capsule formation. ${ }^{8}$ This poses a potential problem for pediatric patients as the heart grows. Moreover, leaving a foreign body in place per se predisposes patients to infection over time. ${ }^{9}$ Furthermore, ePTFE is not transparent, and may interfere with visualization of the cardiac architecture covered with a fibrous capsule underneath an ePTFE sheet during reoperations. Many investigators have reported on the efficacy of xenograft membranes, including equine and bovine pericardium. ${ }^{10}$ However, these membranes are also permanent and opaque.

In contrast, bioresorbable adhesion barriers include solutions containing pharmacologic agents and bioresorbable membranes. ${ }^{9}$ The effectiveness of several agents, including hydrophilic polymers, ${ }^{11}$ hyaluronic acid coating solutions, ${ }^{12,13}$ carboxymethyl cellulose, ${ }^{13}$ and substances containing fibrinolytic drugs ${ }^{14}$ have been reported. Tissue plasminogen activator and streptokinase have also been shown to be effective for reducing adhesion formation. ${ }^{14}$ However, both modalities have the undesirable side effects of bleeding and impairment of wound healing. ${ }^{1}$

\section{Products to prevent adhesions after cardiac surgery with CE mark approval}

To date, five products have received CE mark approval in Europe for reducing the formation of postoperative cardiac adhesions (Table 1). These products include CV-Seprafilm ${ }^{\mathrm{TM}}$ (Genzyme Corp, Cambridge, MA), Cova CARD ${ }^{\mathrm{TM}}$ (Biom'Up,
Lyon, France), CoSeal ${ }^{\circledR}$ surgical sealant (Baxter Healthcare Inc, Deerfield, IL), CardioWrap ${ }^{\circledR}$ (MAST Biosurgery USA Inc, San Diego, CA), and REPEL-CV ${ }^{\circledR}$ (SyntheMed Inc, Iselin, $\mathrm{NJ}$ ). All of these are briefly introduced here. We also give a systematic review of the efficacy and safety of REPEL-CV for preventing postoperative pericardial adhesions.

\section{Hyaluronic acid and carboxymethylcellulose}

CV-Seprafilm (Figure 1) is a sterile and bioresorbable translucent membrane composed of US Pharmacopeia glycerol and two chemically modified anionic polysaccharides, ie, sodium hyaluronate and carboxymethylcellulose. The size of the membrane is approximately $12 \times 12 \mathrm{~cm}$. CV-Seprafilm is packed in a Tyvek holder (DuPont, Wilmington, DE). After placement, CV-Seprafilm membrane rapidly turns into a gel, and the hyaluronic acid component is cleared from the body within 28 days of implantation. The rate of carboxymethylcellulose clearance is less clear. CV-Seprafilm has had European CE mark approval since 1999 for use to reduce the incidence of adhesions following cardiac surgery.

\section{Porcine type I collagen}

Cova CARD (Figure 2) is a sterile, purified porcine type 1 collagen membrane, cross-linked with an oxidized polysaccharide. Under dry shape, the membrane has a thickness of approximately $100 \mathrm{~mm}$ and resorbs fully within six months. After denaturation and proteolysis, fragments are eliminated through the kidneys. Due to the limited number of available studies, ${ }^{16}$ there is currently no substantiated overview of the limitations of this bioresorbable adhesion barrier.

\section{Polyethylene glycol}

CoSeal surgical sealant (Figure 3 ) is composed of two synthetic polyethylene glycol polymer solutions that

Table I Overview of currently available products to prevent cardiac adhesions

\begin{tabular}{|c|c|c|c|c|}
\hline Product & Bioresorbable & Chemical substance & Preparation before use & Reference \\
\hline CV-Seprafilm ${ }^{\mathrm{TM}}$ & Yes & $\begin{array}{l}\text { Sodium hyaluronate and } \\
\text { carboxy-methylcellulose }\end{array}$ & No & $\begin{array}{l}\text { Walther et } \mathrm{al}^{2} \\
\text { Naito et } \mathrm{al}^{4} \\
\text { Vrijland et } \mathrm{al}^{15}\end{array}$ \\
\hline Cova $^{\text {TM }}$ CARD & Yes & Porcine type I collagen & No & Bel et al ${ }^{16}$ \\
\hline CoSeal $^{\circledR}$ & Yes & $\begin{array}{l}\text { Two synthetic polyethylene } \\
\text { glycol polymers }\end{array}$ & Yes & $\begin{array}{l}\text { Napoleone et a }\left.\right|^{18} \\
\text { Cannata et a }\left.\right|^{17} \\
\text { Hendrikx et a }\left.\right|^{19}\end{array}$ \\
\hline CardioWrap ${ }^{\circledR}$ & Yes & poly-L-lactide-co-D,L-lactide & No & Iliopoulos et $\mathrm{a}^{20}$ \\
\hline REPEL-CV ${ }^{\mathbb{B}}$ & Yes & $\begin{array}{l}\text { polylactic acid and } \\
\text { polyethylene glycol }\end{array}$ & Yes & $\begin{array}{l}\text { Pines } E^{21} \\
\text { Pines } E^{22} \\
\text { Schreiber et al }{ }^{23} \\
\text { Lodge et al }{ }^{24}\end{array}$ \\
\hline
\end{tabular}




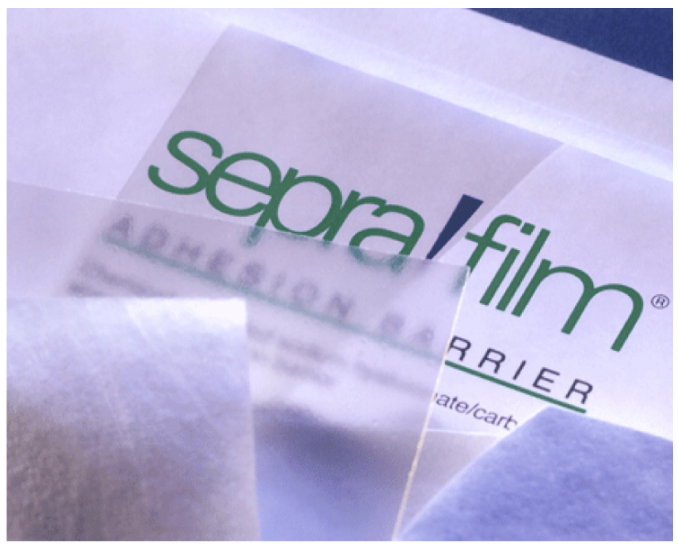

Figure I CV-Seprafilm ${ }^{\circledR}$ adhesion barrier.

rapidly form a biocompatible and strongly adherent hydrogel when admixed with their respective reconstitution buffers. One of these polyethylene glycol polymers adheres to tissue proteins (specifically, amine groups) or synthetic graft material. Because of an up to fourfold increase in its own volume, avoiding mechanical compression of cardiac structures seems to be wise. The agent is applied directly to the operative site using a specially designed delivery system, forming a cohesive matrix within seconds and resorbing fully over several weeks.

\section{Polylactic acid}

The CardioWrap protective sheet (Figure 4) is a bioresorbable translucent membrane composed of L-lactide $(70 \%)$ and D,L-lactide (30\%). CardioWrap is delivered sterile in a multilayered package. Sheets of $10 \times 13 \mathrm{~cm}$ or $13 \times 20 \mathrm{~cm}$ are available. According to the manufacturer, the membrane can be easily repositioned even in a wet environment. More than $80 \%$ of the copolymer remains for the initial eight weeks, but is fully absorbed within six months. The molecules are slowly hydrolyzed into carbon dioxide and water and are released from the body through the lungs.

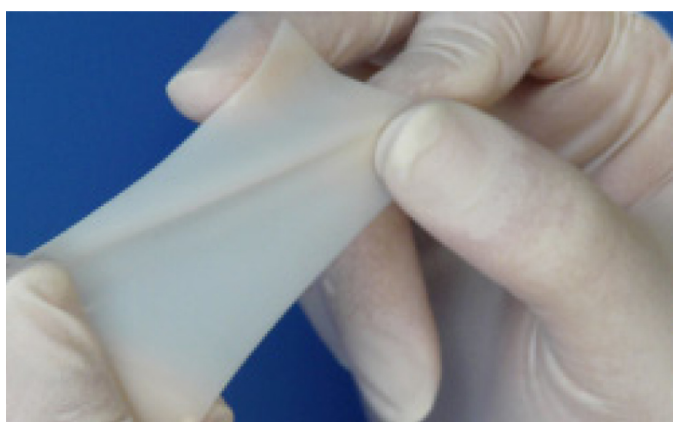

Figure 2 Cova $^{\text {TM }}$ CARD membrane.

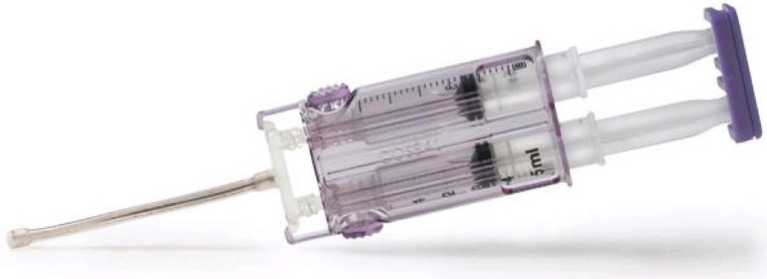

Figure 3 CoSeal ${ }^{\circledR}$ surgical sealant.

\section{Polylactic acid and polyethylene glycol}

REPEL-CV adhesion barrier (Figure 5) is a sterile and bioresorbable transparent barrier film that was formulated to reduce the formation of postoperative adhesions after cardiac surgery. It is a polymeric film comprising of polylactic acid (52\% LA) and polyethylene glycol (47\% EO). The size of the membrane is approximately $18 \times 13.5 \mathrm{~cm}$. The REPEL-CV film is $5.5 \mathrm{~mm}$ thick and packaged in a single-use, foil pouch. The film can easily be shaped to size by trimming the sheet with scissors. Prior to placement the adhesion barrier has to be soaked in Ringer's lactate or saline solution for approximately two minutes, but no longer than five minutes. The material should extend at least $1.5 \mathrm{~cm}$ laterally beyond the pericardial edges when applied to the epicardium. If REPEL-CV is sutured to the pericardium, it should be secured with a 4-0 or larger suture with a tapered needle. Because the copolymer resorbs fully within 28 days, exposed tissue surfaces are re-epithelialized and are therefore no longer prone to adhesion formation.

\section{REPEL-CV}

REPEL-CV is a bioresorbable adhesion barrier and has been commercially available in Europe since September 2006. Originally developed at the Hebrew University of Jerusalem by Daniel Cohn et $\mathrm{a}^{25}$ the technology was released by the Transfer Company of the Hebrew University. Professor Cohn and his colleagues investigated biomedical polymers for use in adhesion barriers and grafts for many years. Before

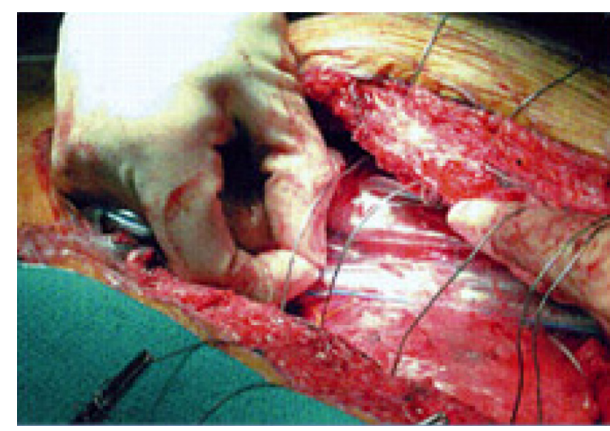

Figure 4 CardioWrap ${ }^{T M}$ protective sheet. 


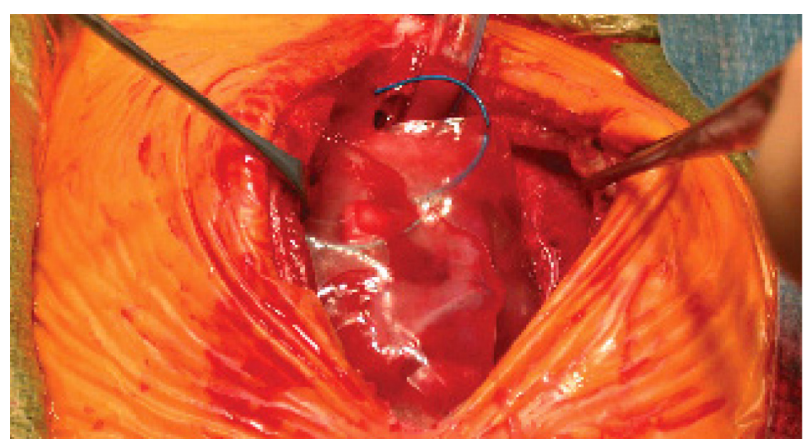

Figure 5 REPEL-CV ${ }^{\circledR}$ adhesion barrier.

REPEL-CV was introduced to the market, an adhesion barrier called REPEL ${ }^{\circledR}$ was the first in the series. Made from a different copolymer formulation, REPEL-CV showed less rapid biodegradation, as well as a higher strength film. In 2007, the US Food and Drug Administration recommended approval of REPEL-CV for use in young adults and pediatric patients (up to 21 years of age) likely to need secondary open heart surgery.

\section{Mechanism of action}

REPEL-CV is intended to provide a temporary mechanical barrier to separate potentially opposing surfaces from interconnecting with each other. It thus serves to reduce postoperative formation of adhesions during the early phase of tissue repair and regeneration. By placing the device over the traumatized tissue surfaces, the formation of interconnecting fibrinous bands between opposing surfaces is prevented and the development of fibrous adhesions is reduced. Yoshioka et al suggested that the polylactide film acts as a scaffold for tissue regeneration which ultimately eliminates adhesions. ${ }^{26}$

\section{Design}

REPEL-CV consists of two types of segments (EO and LA units), each of them rendering polymers with specific properties. ${ }^{25}$ While they are in general defined by their EO/LA acid ratio, they are preferably chain-extended in their microstructure, allowing a degree of mobility and flexibility which is consistent with antiadhesion activity. Due to the proprietary tailor-made design, the enhanced antiadhesion properties of EO (3000-10,000 D), the biodegradability of LA (8-16 units), and the mechanical properties derived from the microstructure of the polymeric matrix are combined..$^{25}$

The advantage of polyethylene glycol is its enhanced antiadhesion properties, even if it is associated with faster polymer degradation. On the other hand, LA is used because of its good biodegradability, at the same time providing the strength required of an effective adhesion barrier. In addition, it is transparent and does not obstruct the surgeon's view of the surgical field. Nevertheless, inflammatory reactions have been reported in the past. ${ }^{27}$

LA is approved for numerous clinical applications, including sutures, bone plates, abdominal mesh, and extended-release pharmaceuticals. In addition, EO is used extensively in a variety of products, including packing material, food additives, cosmetics, and devices in medical and biomedical research, eg, drug delivery and tissue engineering.

By changing the copolymers in their specific EO/LA acid ratio or weight of the molecular components, different conditions (eg, film, gel, dispersion, liquid polymer, spray, or viscous solution) can be achieved. ${ }^{25}$ Okuyama et al reported on two single preclinical studies using a rabbit and canine model on three films of various $\mathrm{EO} / \mathrm{LA}$ acid ratios $(\mathrm{EO} / \mathrm{LA}=1.5$, REPEL-CV; EO/LA $=2.5$ and EO/LA $=3.0$, REPEL).,${ }^{5,28} \mathrm{All}$ bioresorbable membranes (EO/LA $=1.5,2.5$, and 3.0) were found to reduce adhesion formation significantly, with $\mathrm{EO} /$ LA $=1.5$ (REPEL-CV) being optimal. The mean tenacity and density scores of adhesions formed in the treated groups were significantly less than for the control groups (Figures 6 and 7). The film with an EO/LA ratio of 3.0 was too fragile for clinical use.

Because of the specific composition and molecular architecture of REPEL-CV, the film possesses defined mechanical strength. In a hydrated tensile strength study, ${ }^{29}$ REPEL films were hydrated for specific time periods,

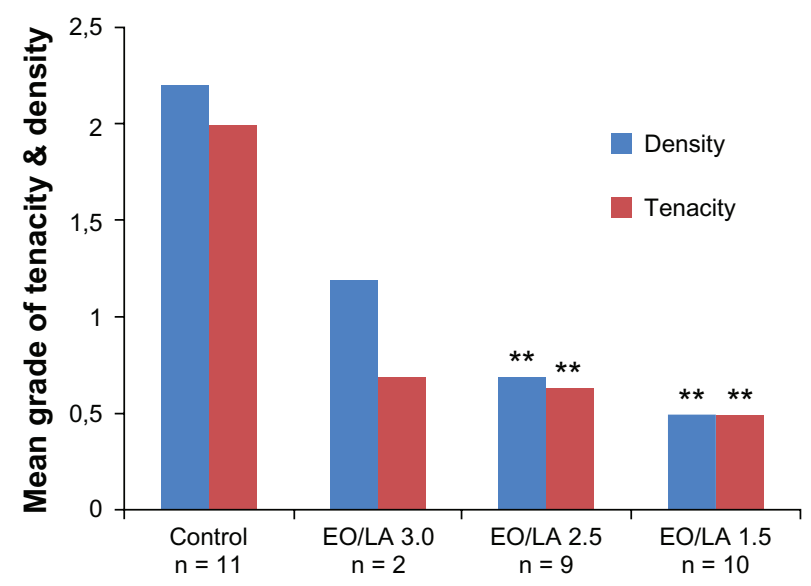

Figure 6 Overall mean adhesion scores for tenacity and density for each group in model I (pericardial adhesions). Each group was compared with the control group $(* * p<0.05)$.

Copyright ( 1 1999, Elsevier. Modified with permission from Okuyama N, Wang CY, Rose EA, et al. Reduction of retrosternal and pericardial adhesions with rapidly resorbable polymer films. Ann Thorac Surg. 1999;68:913-918.

Abbreviations: EO, polyethylene glycol; LA, polylactic acid. 


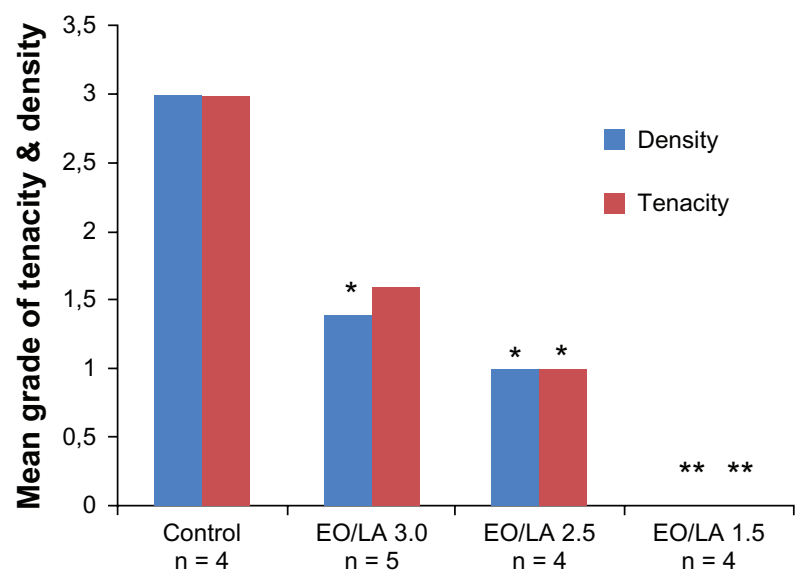

Figure 7 Overall mean adhesion scores for tenacity and density for each group in model I (retrosternal adhesions).

Copyright (C) 1999, Elsevier. Modified with permission from Okuyama N, Wang CY, Rose EA, et al. Reduction of retrosternal and pericardial adhesions with rapidly resorbable polymer films. Ann Thorac Surg. 1999;68:913-918.

Abbreviations: EO, polyethylene glycol; LA, polylactic acid.

and the tensile strength and suture pullout strength were determined. The results demonstrated that, with increasing hydration time, both the tensile strength and suture pullout strength decreased. A minimum of 400 psi was determined as an acceptable hydrated tensile strength, but a minimum value of 900 psi was chosen for REPEL-CV. This ensures that even if the membrane was to lose as much as $50 \%$ of its hydrated tensile strength it would still provide the strength required of an effective adhesion barrier. Furthermore, in a preclinical study in New Zealand rabbits, the material with higher levels of LA (REPEL-CV) was able to hold sutures for longer periods, and maintained integrity for at least 16 hours postoperatively. ${ }^{29}$

The rate of resorption was assessed histologically in a surgical subcutaneous implantation study in the rats. ${ }^{29}$ At days 3,7 , and 14 , there were portions of implants and capsule formation up to $0.5 \mathrm{~mm}$ visible in all animals. By day 29, the adhesion barrier was no longer visible. At days 7, 14, and 29, the adhesion barrier was considered a nonirritant. In addition, a 28-day biocompatibility study ${ }^{29}$ in the rabbit indicated no untoward or gross histological reactions.

Due to the two types of segments, resorption of REPEL-CV follows two biological cascades. EO is rapidly removed from the body unaltered through renal excretion $(>90 \%)$, with clearance rates inversely proportional to polymer molecular weight. ${ }^{30}$ On the other hand, LA is processed through autocatalytic hydrolysis into separate lactic ester chains (rate-determining step). Finally, the liver degrades these ester chains into carbon dioxide and water, eliminating these end products through the lungs.

\section{Clinical efficacy and safety}

According to Lodge et al, ${ }^{24}$ the severity of adhesions can be classified as: Grade 0, no adhesions; Grade 1, mild (filmy, noncohesive, requiring blunt dissection only); Grade 2, moderate (filmy, noncohesive, requiring combined sharp and blunt dissection); and Grade 3, severe (dense, cohesive, requiring extensive sharp dissection). Clinical data from four trials conducted over a 10-year period are available. ${ }^{21-24}$ These analyses include three small feasibility studies enrolling 13-27 patients each and a short-term safety study.

In the first clinical study of 27 adults, it was shown that REPEL-CV did not present an additional risk to patients undergoing cardiothoracic surgery. ${ }^{21}$ During this small unpublished, single-blinded, randomized safety study, the adverse event profiles were similar between treated and control groups. Nevertheless, severe adhesions were noted in two left ventricular assist device patients. One of them had a history of coagulopathy, as well as several risk factors, including sepsis, re-explorative surgery, and the administration of heparin subcutaneously, and developed a coagulopathy approximately 3.5 months after the placement of REPEL-CV. It is assumed that the dynamic mechanical stress generated by the large pulsating outflow graft of the left ventricular assist device prematurely disrupted the integrity of the adhesion barrier. Therefore, REPEL-CV is considered to be contraindicated in patients in whom a ventricular assist device is implanted.

The second study was undertaken in 13 neonate patients with hypoplastic left heart syndrome following palliative pediatric cardiac surgery. At the time of the second sternotomy (after 2-8 months) there were no dense adhesions ( $0 \%)$ in the REPEL-CV treatment group and $66.6 \%$ in the control group, suggesting a reduction in the extent and severity of postoperative adhesions. Because of the small sample size of seven patients (three REPEL-CV-treated versus four controls $)$, only a trend towards statistical difference $(P=0.062)$ was seen for the reduction of dense adhesions. ${ }^{22}$ The adverse event profiles were similar between the treated and control patients.

In 2007, Schreiber et al reported on 15 neonates in an uncontrolled, multicenter trial who required a staged series of surgical corrections of congenital heart malformations. ${ }^{23}$ In this study, $86.7 \%$ of patients had no Grade 3 adhesions (severe, dense, cohesive) at the investigational surgical site (no control group). The mean percentages of the investigational surgical sites having Grade $0,1,2$, and 3 adhesions were $9 \%, 61 \%, 19 \%$, and $11 \%$, respectively. Five severe adverse events were observed in this study (three 
deaths, one shunt revision, and one cerebral cramp), but none were determined to be related to the product. Additionally, no signs of localized infections were found. The REPEL-CV barrier was completely resorbed in all 15 patients at the time of reoperation $2-8$ months after the initial procedure.

The fourth and major study was a US pivotal multicenter, randomized, controlled trial comparing safety and effectiveness in 142 neonates undergoing staged cardiovascular procedures to correct congenital cardiac malformations. ${ }^{24}$

Even though time to second sternotomy was comparable in both groups ( $169 \pm 70$ days and $160 \pm 56$ days, $P=0.4844$ ), the REPEL-CV-treated group had significantly fewer severe adhesions and significantly milder adhesions than the control group. The overall adhesion distribution was significantly more favorable for the group treated with REPEL-CV (Table 3, Figure 8). With regard to safety, Lodge et al found no difference in the rate of prospectively defined adverse events as well as serious adverse events between the barrier and control group (6 versus $1, P=0.1167$ and 4 versus $0, P=0.1203$ ). ${ }^{24}$ The overall death rate in both groups was comparable $(16 \%$ versus $13 \%, P=0.6405)$. There was evidence that REPEL-CV did not pose any additional risk for mediastinitis or systemic infection. At the time of second sternotomy, four cardiac injuries were reported in each group. All cardiac injuries involved premature entry into the right atrium, the majority of which were not covered by the barrier film as specified by the study protocol. Thus, the study material seems to be safe when used in pediatric patients with delayed sternal closure.

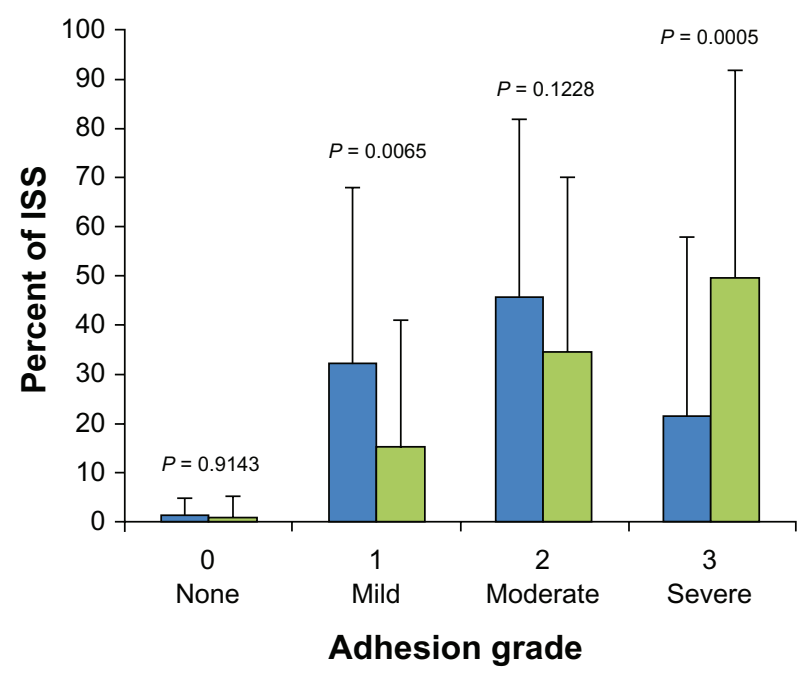

Figure 8 Distribution of adhesions at the ISS by severity grade between the REPEL-CV ${ }^{\circledR}$ (blue bars) and control (green bars) group.

Copyright (C) 2008, Elsevier. Lodge AJ, Wells WJ, Backer CL Jr. A novel bioresorbable film reduces postoperative adhesions after infant cardiac surgery. Ann Thorac Surg. 2008;86:6I4-62I. ${ }^{24}$

Abbreviation: ISS, investigational surgical site.
Summarizing the limited clinical data, REPEL-CV reduced the severity but not the incidence of adhesions, and there was no beneficial effect of the study product on dissection time or reduction of sternal re-entry complications. However, it has to be highlighted that the definition of the extent of adhesions was not uniform in the literature, but all trials showed that the use of REPEL-CV significantly reduced the extent of postoperative adhesions (Table 2).

\section{Tolerability}

In an antimicrobial preservative effectiveness study it was shown that REPEL did not support any bacterial growth. ${ }^{29}$ Okuyama et al found a markedly reduced inflammatory response in treated animals during histological examination ${ }^{28}$ (Figure 9). Additionally, capsule formation induced by permanent or slowly resorbed barriers was avoided. ${ }^{28}$

\section{Compatibility}

The safety and compatibility of REPEL-CV was determined in a series of 16 preclinical studies conducted by North American Science Associates Inc (Northwood, OH). ${ }^{29}$ The bioresorbable adhesion barrier was shown to be nontoxic and biocompatible. ${ }^{29}$

\section{Current place in therapy}

Postoperative adhesions remain a challenging problem in cardiac surgery. Optimal means to prevent adhesions are not available at present. Different techniques to replace the pericardium, as well as to decrease the extent and severity of adhesions have been applied. However, no definitive method has yet evolved. Different agents, such as prosthetic barriers, ${ }^{4,6}$ xenograft materials, ${ }^{10}$ solutions containing pharmacological substitutes, ${ }^{11-13}$ bioresorbable membranes, ${ }^{2,18,20}$ and medical anti-inflammatory drugs ${ }^{31}$ have been published. Nevertheless, none of these approaches has proven optimal effectiveness.

Pitfalls of the current materials and agents include technical difficulties with surgical application, such as the need for complete hemostasis, removal of extraperitoneal fluid, and concerns about constriction and fibrosis. Furthermore, previously studied products have been reported to be difficult to handle in the operating theater. ${ }^{2}$ Thus, there is still a need for a universal, safe, effective, and easy-to-use material to reduce surgical adhesions in a significant manner. This would be extremely helpful in cardiac as well as in general surgery during staged procedures. ${ }^{2}$

The rationale for using a bioresorbable membrane is to provide a temporary mechanical barrier that reduces or prevents the formation of adhesions during the early phases 
Table 2 Overview of studies focusing of REPEL-CV® to prevent cardiac adhesions

\begin{tabular}{|c|c|c|c|c|}
\hline \multirow[t]{2}{*}{ Author } & \multirow[t]{2}{*}{ Patients (n) } & \multirow[t]{2}{*}{ Age } & \multicolumn{2}{|l|}{ Benefit } \\
\hline & & & Efficacy & Safety \\
\hline Pines $E^{2 l}$ & 27 & $18-65$ years & & No additional risk ${ }^{\dagger}$ \\
\hline Pines $\mathrm{E}^{22}$ & 13 & $\mathrm{I}-7$ years & Extent + severity $\downarrow$ & No additional risk ${ }^{\dagger}$ \\
\hline Schreiber et al ${ }^{23}$ & 19 & 4-54 days & Extent + severity $\downarrow$ & No signs of localized infection \\
\hline Lodge et $\mathrm{a}^{24}$ & 142 & 2-93 days & Extent + severity $\downarrow$ & No additional risk ${ }^{\dagger \ddagger}$ \\
\hline
\end{tabular}

Notes: †evidence for equality between treated and control group; ‘adverse events, severe adverse events, clinical laboratory tests, concomitant medication, physical examination, mortality.

of tissue repair. Therefore, application of REPEL-CV seems to be feasible. However, even if the membrane is comfortable to handle and easy to apply, it should still be soaked in Ringer's lactate or saline prior to implantation for optimal results. Therefore, a sprayable substance would probably be even easier to handle. ${ }^{2}$

According to preclinical and clinical results, REPEL-CV adhesion barrier has proven effectiveness in reducing the extent and severity of surgical adhesions, with the potential to facilitate reoperation in repeat median sternotomies. The membrane is applicable for both pediatric and adult cardiac surgical patients. In all instances, use of such a membrane leads to a relevant reduction in the risk of repeat surgical thoracotomy and thus is of clinical benefit for the individual patient.

Regarding the dissection time of adhesions, no significant difference was found even though it was determined that overall dissection time was reduced when less severe adhesions were present. Because dissection techniques vary substantially from surgeon to surgeon and with patient anatomy, in addition to the multiple confounding variables, it remains questionable if such a measure can be proven using a multicenter design.

The small number of cardiac injuries attributed to dissection likely reflects the familiarity of congenital heart surgeons with reoperative surgery. However, especially in less experienced hands, such as those of surgical trainees, fewer adhesions may facilitate sternal re-entry. ${ }^{24}$

A combination of use of a resorbable membrane and an ePTFE membrane would eventually be of added benefit. ${ }^{2}$ In clinical practice, covering the right atrium or whatever

Table 3 Degree of adhesion formation as a percentage of investigational surgical site assessed at the second sternotomy

\begin{tabular}{lccc}
\hline Percent of ISS & Barrier & Control & P value \\
\hline Grade 0 (no adhesions) & $1.1 \pm 3.8$ & $1.0 \pm 4.7$ & 0.9143 \\
Grade I (mild adhesions) & $32.2 \pm 35.9$ & $15.0 \pm 26.4$ & 0.0065 \\
Grade 2 (moderate adhesions) & $45.6 \pm 36.4$ & $34.5 \pm 35.6$ & 0.1228 \\
Grade 3 (severe adhesions) & $21.1 \pm 36.9$ & $49.5 \pm 42.7$ & 0.0005 \\
\hline
\end{tabular}

Note: Modified from Lodge et al. ${ }^{24}$

Abbreviation: ISS, investigational surgical site. structures are deemed to be most at risk of injury with the absorbable barrier film may be prudent. ${ }^{24}$

The indications for an adhesion barrier seem to be in patients receiving planned staged approaches (including Norwood or functional single ventricle procedures) and patients who eventually require repeat intervention for valve reconstruction (single or combined valve surgery), atrioventricular septal defect, or tetralogy of Fallot repair.
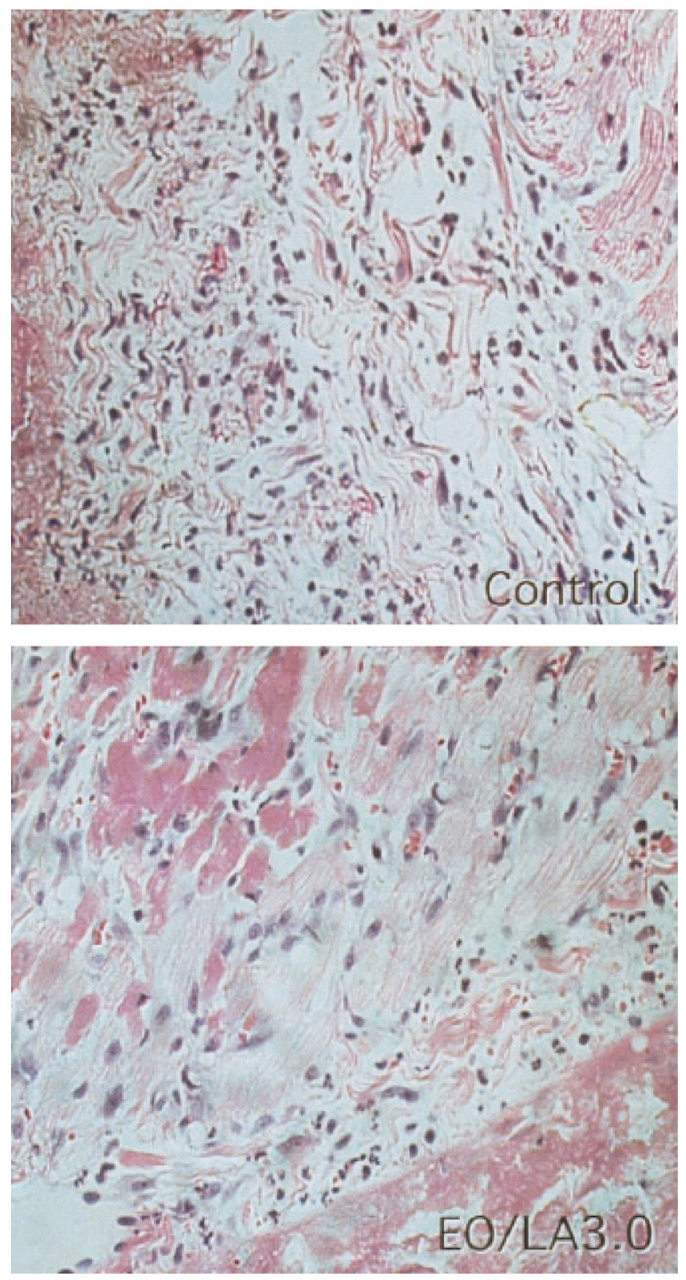

Figure 9 Hematoxylin and eosin-stained specimens of the right ventricular wall from beneath the sternum 72 hours after operation. A reduction of the inflammatory area and amount of inflammatory cells was seen in the animal treated with EO/LA $=3.0$ film (right) compared with the control animal (left). Original magnification, 120x. Abbreviations: EO/LA, polyethylene glycol/polylactic acid ratio. 
Adult patients who may require a repeat intervention within 1-5 years would clearly benefit. This would include patients with complex heart valve repair or potential transplant candidates. Because there was no evidence for increased risk of infection or mediastinitis, there is no disadvantage when using it in the individual patient.

The cost-effectiveness has to be considered as well. Ease and reduced duration of repeat surgical procedures will always justify the use of the membranes. Sometimes it will be difficult to foresee exactly which patients will require reoperation. However, general use of a bioresorbable membrane may be restricted due to financial issues. ${ }^{2}$

To conclude, REPEL-CV is a product that is comfortable to handle and easy to apply in the operating room. It has been found to be safe in both preclinical and clinical use. REPEL-CV is effective in reducing both the severity and extent of postoperative adhesions after cardiac surgery. It was found to be safe and effective when used in patients having delayed sternal closure. Further study is warranted to determine its effects on reducing operative time and preventing cardiac injury in those patients who require repeat median sternotomy.

\section{Disclosure}

The authors report no conflicts of interest in this work.

\section{References}

1. Konertz WF, Kostelka M, Mohr FW, et al. Reducing the incidence and severity of pericardial adhesions with a sprayable polymeric matrix. Ann Thorac Surg. 2003;76:1270-1274.

2. Walther T, Rastan A, Dähnert I, et al. A novel adhesion barrier facilitates reoperations in complex congenital cardiac surgery. JThorac Cardiovasc Surg. 2005;129:359-363.

3. Jacobs S, Holzhey D, Walther T, Falk V, Mohr FW. Redo minimally invasive direct coronary artery bypass grafting. Ann Thorac Surg. 2005;80:1336-1339.

4. Naito Y, Shin'oka T, Hibino N, Matsumura G, Kurosawa H. A novel method to reduce pericardial adhesion: A combination technique with hyaluronic acid biocompatible membrane. J Thorac Cardiovasc Surg. 2008;135:850-856.

5. Okuyama N, Rodgers KE, Wang CY, et al. Prevention of retrosternal adhesion formation in a rabbit model using bioresorbable films of polyethylene glycol and polyactic acid. J Surg Res. 1998;78: $118-122$.

6. Laks H, Hammond G, Geha AS. Use of silicone rubber as a pericardial substitute to facilitate reoperation in cardiac surgery. JThorac Cardiovasc Surg. 1981;82:88-92.

7. Copeland JG, Arabia FA, Smith RG, Covington D. Synthetic membrane neo-pericardium facilitates total artificial heart explantation. $J$ Heart Lung Transplant. 2001;20:654-656.

8. Ozeren M. Foreign body reaction to polytetrafluoroethylene. Interact Cardiovasc Thorac Surg. 2008;7:276-277.

9. Tsukihara H, Takamoto S, Kitahori K, et al. Prevention of postoperative pericardial adhesions with a novel regenerative collagen sheet. Ann Thorac Surg. 2006;81:650-657.
10. Gabbay S, Guindy AM, Andrews JF, Amato JJ, Seaver P, Khan MY. New outlook on pericardial substitution after open heart operations. Ann Thorac Surg. 1989;48:803-812.

11. Duncan DA, Yaacobi Y, Goldberg EP, et al. Prevention of postoperative pericardial adhesions with hydrophilic polymer solutions. J Surg Res. 1988;45:44-49.

12. Mitchell JD, Lee R, Hodakowski GT, et al. Prevention of postoperative pericardial adhesions with a hyaluronic acid coating solution. J Thorac Cardiovasc Surg. 1994;107:1481-1488.

13. Seeger JM, Kaelin LD, Staples EM, et al. Prevention of postoperative pericardial adhesions using tissue-protective solutions. J Surg Res. 1997;68:63-66.

14. Topal E, Ozturk E, Sen G, Yerci O, Yilmazlar T. A comparison of three fibrinolytic agents in prevention of intra-abdominal adhesions. Acta Chir Belg. 2010;110:71-75.

15. Vrijland WW, Tseng LN, Eijkman HJ, et al. Fewer intraperitoneal adhesions with use of hyaluronic acid-carboxymethylcellulose membrane: A randomized clinical trial. Ann Surg. 2002;235: 193-199.

16. Bel A, Kachatryan L, Bruneval P, et al. A new absorbable collagen membrane to reduce adhesions in cardiac surgery. Interact Cardiovasc Thorac Surg. 2010;10:213-216.

17. Cannata A, Taglieri C, Russo CF, Bruschi G, Martinelli L. Use of CoSeal in a patient with a left ventricular assist device. Ann Thorac Surg. 2009;87:1956-1958.

18. Napoleone CP, Valori A, Crupi G, et al. An observational study of CoSeal for the prevention of adhesions in pediatric cardiac surgery. Interact Cardiovasc Thorac Surg. 2009;9:978-982.

19. Hendrikx M, Mees U, Hill AC, Egbert B, Coker GT, Estridge TD. Evaluation of a novel synthetic sealant for inhibition of cardiac adhesions and clinical experience in cardiac surgery procedures. Heart Surg Forum. 2001;4:204-209.

20. Iliopoulos J, Cornwall GB, Evans RN, et al. Evaluation of a bioresorbable polylactide film in a large animal model for the reduction of retrosternal adhesions. J Surg Res. 2004;118:144-153.

21. Pines E. A comparative, evaluator-blinded, randomized, parallel study to determine the safety of REPEL-CV ${ }^{\circledR}$ for reducing post-operative adhesions following adult cardiothoracic surgery. Unpublished research. 1999 Jun [cited 2010 Oct 24];[about 5 p.]. http://www.synthemed.com/ cmsdocuments/Adult_Clinical_Experience_with_REPEL-CV.pdf. Accessed Oct 242010.

22. PinesE. A comparative, evaluator-blinded, randomized, parallel study to determine the safety and effectiveness of REPEL-CV ${ }^{\circledR}$ for reducing post-operative adhesions following pediatric cardiothoracic surgery. Unpublished research. 2003 Feb [cited 2010 Oct 24]; [about 7 p.]. http://www.synthemed.com/ cmsdocuments/Pediatric_Clinical_Experience_with_REPEL-CV.pdf. Accessed Oct 242010

23. Schreiber C, Boening A, Kostolny M, et al. European clinical experience with REPEL-CV. Expert Rev Med Devices. 2007;4: 291-295.

24. Lodge AJ, Wells WJ, Backer CL Jr. A novel bioresorbable film reduces postoperative adhesions after infant cardiac surgery. Ann Thorac Surg. 2008;86:614-621.

25. Cohn D, inventor; Synthemed Inc., assignee. Methods and compositions for reducing or eliminating post-surgical adhesion formation. United States Patent US 7202281. Apr 102007.

26. Yoshioka I, Saiki Y, Sakuma K, et al. Bioabsorbable gelatin sheets latticed with polyglycolic acid can eliminate pericardial adhesion. Ann Thorac Surg. 2007;84:864-870.

27. Dawes E, Rushton N. Response of macrophages to poly(L-lactide) particulates which have undergone various degrees of artificial degradation. Biomaterials. 1997;18:1615-1623.

28. Okuyama N, Wang CY, Rose EA, et al. Reduction of retrosternal and pericardial adhesions with rapidly resorbable polymer films. Ann Thorac Surg. 1999;68:913-918. 
29. US Food and Drug Administration. [homepage on the Internet]. Bethesda MD: US Food and Drug Administration; c1927-10 [updated 2010 Oct 13; cited 2010 Oct 24]. Available from: http://www.fda. gov/ohrms/dockets/ac/07/briefing/2007-4318b1-03SSED \%20 Word\%207-23-07_Final.pdf. Accessed Oct 242010.

30. Webster R, Didier E, Harris P, et al. PEGylated proteins: Evaluation of their safety in the absence of definitive metabolism studies. Drug Metab Dispos. 2007;35:9-16.
31. Iskesen I, Aksoy O, Cerrahoglu M, Sirin H. The effect of piroxicam on the prevention of postoperative retrosternal and pericardial adhesions. Acta Cardiol. 2007;62:559-564.

\section{Publish your work in this journal}

Medical Devices: Evidence and Research is an international, peerreviewed, open access journal that focuses on the evidence, technology, research, and expert opinion supporting the use and application of medical devices in the diagnosis, treatment and management of clinica conditions and physiological processes. The identification of novel devices and optimal use of existing devices which will lead to improved clinical outcomes and more effective patient management and safety is a key feature. The manuscript management system is completely online and includes a quick and fair peer-review system. Visit http://www. dovepress.com/testimonials.php to read real quotes from authors.

Submit your manuscript here: http://www.dovepress.com/medical-devices-evidence-and-research-journal 